\title{
ROLE OF PHYLLOSPHERIC BACTERIA IN BIOCHEMICAL MECHANISM OF SALINITY STRESS ALLEVIATION IN Centella asiatica
}

\author{
SONAL GUPTA ${ }^{\mathrm{a} 1}$ AND ASHWINI A. WAOO \\ ${ }^{a b}$ Department of Biotechnology, A.K.S. University, Satna, M.P. India
}

\begin{abstract}
S
Phytochemical or biochemical preparation of various plants like Centella asiatica contains various biologically active compounds and its analysis will provide an opportunity for new drugs lead. Due to their medical importance, there is always a need to cultivate these plants at large scale. In current scenario high population explosion demands for more crop productivity, but crop productivity is adversely affected by increasing abiotic stress like soil salinization. High salinity adversely affects plant growth because it increases osmotic potential gradient of soil which further decreases water and nutrient uptake ability of plant roots from soil. Low water and nutrient availability inhibits various vital activities of plant. Various important amino acids (like proline, methionine etc) help plant to alleviate or tolerate abiotic stresses like soil salinity. Abiotic stress tolerance mechanism in Plant cells include remodeling of their gene expression which results in corresponding alteration in the intracellular levels of such stress alleviating metabolites like amino acids in plant cells. Development of methods, to improve stress tolerance against soil salinization in plants, is a strategy to deal with negative impacts of harsh environmental conditions on plants. Exploitation of beneficial microflora present in phyllosphere of plant provides a new platform for improving salinity tolerance in the plant. Bacteria are the most abundant inhabitants of the phyllosphere. This review focuses on stress alleviation mechanism attributed by Phyllosphere bacteria in plant. Recent biochemical and molecular studies in plant biotechnology have provided insights into metabolic network of plant-microbe interaction that enhance salinity tolerance. The significance of phyllosphere microbiome includes regulation of biosynthesis of stress alleviating sulfur containing metabolites like amino acids, vitamins in host plant. Sulfur metabolites are useful to alleviate salinity stress in plants due to their ion scavenging ability which results in osmotic balance. This review signifies the role of phyllospheric bacteria in remodeling of various metabolic activities of host plant that confer salinity tolerance
\end{abstract}

KEYWORDS: Abiotic Stress, Abiotic Stress Tolerance, Amino Acids, Centella asiatica, Phyllosphere, Soil Salinization, Sulfur Containing Metabolites

In present Anthropocene era, climatic conditions are continuously changing due to various human activities which further created many environmental stressors like soil salinity. Water and land are two vital parameters for agriculture. Salinity involves increase in salt concentration of soil and water and this excessive salt concentration negatively affects crop productivity worldwide. So, Agricultural organizations conduct many researches to develop a significant control mechanism which helps to influence stress tolerance activity of plants against salinity. By increasing the productivity of commercially significant crop plants we can fulfill the demand of large scale world population. One of the economically and commercially important plants is Centella asiatica. There were varieties of researches conducted previously on Centella asiatica plant. Among these, certain reviews are concerned with detail study of morphology, geographical distribution, phytochemical characteristics and composition of Centella asiatica plant (Singh et al., 2010). It is used as a culinary vegetable and medicinal herb. The plant has great economical and commercial significance. Large scale cultivation of this plant is required by commercial cultivars. In current scenario soil salinization has affected a large proportion of agricultural land and become an important obstacle to achieve the desired yield of such commercial plants. Significant reviews and informations are available which focus on certain factors which facilitate or promote plant growth by increasing stress tolerant mechanism against salinity. Among these factors, plant microbiome plays an important role in plant growth promotion. Phyllospheric or arial parts of plant body extensively populated by varieties of microflora. Some phyllospheric microflora especially bacteria exerts positive impacts on host plant metabolism and growth. The present review involves study and evaluation of growth promoting phyllospheric bacterial population of Centella asiatica (Muller et al., 2003) and also elaborates their role in enhancement of stress tolerance mechanism of the plant against salinization. Such studies lead the development of various biological preparations containing phyllospheric bacterial inoculants which promote stress tolerance

${ }^{1}$ Corresponding author 


\section{GUPTA AND WAOO: ROLE OF PHYLLOSPHERIC BACTERIA IN BIOCHEMICAL MECHANISM OF SALINITY ...}

mechanism in host plants and further improve crop productivity.

\section{Centella asiatica}

Centella asiatica commonly called as Centella, Gotu kola or Asiatic pennywort. It is a herbaceous, perennial plant of family Apiaceae. It is native to wetlands in Asia. It grows in temperate and tropical swampy areas in many world regions. Many reviews help us to know economical and medical significance of Centella asiatica. Centella asiatica plant extract contains various biologically and pharmacologically active compounds, which are known to have therapeutic effects against various diseases (Brinkhaus et al., 2000). It also has potential to monitor various heavy metal pollution levels in soil and to control various species of weeds. The plant is a small trailing herb and it is the only species of Centella found in India. Its stem is glabrous, pink striated and rooting at nodes. Leaves of the plant are fleshy, orbicular to reniform and dentate. Petiole is long, smooth on upper surface and hairy below. Flowers are pink and white in fascicled umbels. The fruits are oblong, dull brown and laterally compressed pericarp hard, thickened and woody. Centella contains pentacyclic triterpenoids, asiaticoside, brahmoside, asiatic acid and brahmic acid (Hashim et al., 2011). These phytochemicals are used to treat various disorders, minor wounds, to encourage lactation, headache, nausea, and drowsiness etc (James et al., 2009). Previous researches also revealed beneficial role of Centella asiatica in epithelial cell proliferation and help in sound healing (Ruszymah et al., 2012).Centella asiatica plant is already studied for having anxiolytic properties (Wijeweera et al., 2006).

\section{ABIOTIC STRESSES AND THEIR IMPACT ON PLANT}

\section{(In special reference of Soil Salinization)}

Like all forms of life, plant growth is also depends on its surrounding. Plant surrounding consists various biotic and abiotic factors which altogether affect plant growth. The non living variables of any environment are known as abiotic factors. Abiotic factors are natural, intangible and inanimate factors like temperature, drought, sunlight, wind and soil salinity. When the level of these abiotic factors varies from their optimum range, it creates an abiotic stress on plant growth and productivity (Negrao et al., 2017).
Among these soil salinity or soil salinization is a major abiotic stress which significantly affects plant growth (Hirayama et al., 2010). Soil salinization is an accumulation of water soluble salts to extents that adversely affect plant growth and productivity. Soil composition is very important for plant growth because it consists water and various minerals which promote plant growth. Plant uptakes water and minerals from soil by its roots. High salinity is harmful for plant because it alters or increases osmotic potential gradient which leads excessive transportation of various ions $\left(\mathrm{Na}^{+}, \mathrm{Cl}^{-}\right)$from soil to plant cells. High salinity of soil also causes over production of reactive oxygen species (ROS) that leads increased redox state of plant cell. Consequence of intracellular accumulation of ROS is breakdown of various biomolecules like protein, lipid, nucleic acid etc in plant cell which results cellular death and diminishes productivity of plants. Reviews show that the higher concentration of salts in soil decrease germination ability of Centella asiatica plant seeds (Devkota et al., 2010).

\section{ABIOTIC STRESS TOLERANCE IN PLANT}

Plants has inbuilt mechanism to alleviate the harmful impacts of various abiotic stresses like soil salinization. This stress alleviation mechanism of plants against soil salinity involves role of various plant metabolites (Gill et al., 2009). Plants are able to sense any change in their environment and respond accordingly. This response involves complex network of cell signaling to regulate gene expression which further leads appropriate modification in metabolic pathways in plant cells (Kumar et al., 2017). Modified concentration of various metabolites help to leach out toxic ions from plant cells and protect them from adverse impact of soil salinization. Significant informations are available which revealed the contribution of various amino acids like proline (Szabados et al., 2009), methionine and its related compounds (Ogawa et al., 2011) in alleviation of soil salinity stress by various plants.

\section{PHYLLOSPHERE MICROFLORA}

Plant body provides a suitable habitat for microbial growth and development. Like roots, above ground structures of plant body are also highly colonized with varieties of micro organisms (Andrews et al., 2000). Microbial inhabitants that grow on aerial parts of plant body called phyllosphere. This phyllospheric microbial 


\section{GUPTA AND WAOO: ROLE OF PHYLLOSPHERIC BACTERIA IN BIOCHEMICAL MECHANISM OF SALINITY...}

community is diverse and affected by host plant itself (Vorholt et al., 2012). Knowledge based on previous researches shows that leaves of plant are highly populated by varieties of microorganisms like bacteria, fungus, algae etc. Leaf of a plant exposed to fluctuating physical parameters like temperature, humidity etc. varieties of bacteria are able to resist this hostile environment on of leaf and populate it. Some bacteria grow on surface of leaves called epiphytic bacteria (Fürnkranz et al., 2008) while others are endophytic bacteria that invade interior of leaf. Many culture methods used to isolate microflora from plant phyllosphere (Mazinani et al., 2017). Cultured microflora has been identified by using biochemical tests. Due to continuous advancements in biotechnology microbial population can be identified at genetic level by using high throughput sequencing methods (Xie et al., 2015). Various studies suggested that phyllospheric micro flora has direct interaction with host plant (Kembel et al., 2014). Sometimes plant and its phyllospheric microbes interact symbiotically and benefit each other. Some species of phyllospheric bacteria have potential to facilitate host plant growth, development and fitness.

\section{SALINITY TOLERANCE MEDIATED BY PHYLLOSPHERIC BACTERIA}

As we know that plant microbiome helps to improve physiological and biochemical activities in host plant (Numan et al., 2018). Microbial population populates plant body, grow on host plant and perform various metabolic procedures. During microbial metabolism various kinds of products and metabolites are formed. Microbial metabolites produced by plant microbiome play role in plant microbial interactions. Phyllospheric microflora makes an essential part of plant microbiome and always provides a base for studies which help to find out advance methods of crop improvements. Researches showed that phyllospheric bacterial populations are known to have significant role in stress tolerance mechanism against soil salinity by host plants (Jalili et al., 2009). Plant cells synthesize elevated concentration of certain metabolites under abiotic stress conditions which help them to adopt such stress conditions. Various researches specified effects of phyllospheric microbiome on host plant metabolism and regulate biosynthesis of various abiotic stresses alleviating metabolites which contribute in abiotic stress alleviation (Ruppel et al., 2012).

\section{PLANT METABOLITES HELP IN STRESS TOLERANCE}

Salinity is an important abiotic stress which negatively affects growth at physiological, metabolic and molecular levels and decrease crop productivity. Plants are adopted various mechanisms to alleviate the negative impacts of high salinity on their productivity. Plants cope with high redox and osmotic stress caused by salinity through improved metabolism which further maintains higher levels of certain metabolites in cell. Living organisms consist various essential elements like $\mathrm{C}, \mathrm{H}, \mathrm{O}$, $\mathrm{N}, \mathrm{S}$ etc. Among all these elements $\mathrm{S}$ occupies fourth place. Sulfur is an important element of various plant metabolites like amino acids, vitamins, polysaccharides, cofactors etc. These sulfur containing metabolites regulate wide range of vital processes in plants. Researches suggested that intracellular levels of sulfur containing metabolites in plant cells play major role in stress tolerance mechanism against salinization due to their ion scavenging properties (Khan et al.,). Sulfur containing amino acids like methionine, cysteine is known to as an essential precursor of metabolic pathways of sulfur metabolism. So, such amino acids have significant importance in signaling and regulation of sulfur metabolism under salinity stress conditions. Studies revealed salinity stress tolerance of plant has been correlated with increased concentration of sulfur containing amino acids. In current scenario, it is necessary to focus our studies on certain factors that induce sulfur metabolism and develop new methods to salinity tolerance in plants. Phyllospheric bacterial population of plant is known to induce stress tolerance ability (Lata et al., 2018).

\section{CONCLUSION}

Production of desired quantity of commercially significant crops for global population requires sustainable agricultural practices which benefit producers, consumers and protect environment also. But, salinity is a major constraint to achieve this objective. In Anthropocene era, salinity is prevailing in environment due to many reasons. Crop plants are able to adopt themselves and tolerate high salt concentration of soil that results in increased productivity of the crop. It is necessary to develop control measures which lead higher productivity of various commercial cultivars like Centella asiatica. Plant associated microbiome especially phyllospheric bacteria can significantly contribute in metabolic and biochemical 
mechanism against salinity stress and conferring elevated tolerance to host plant. Such plant friendly bacterial inoculants can be used as a biocontrol agent against salt stress. Despite informations and reviews are available in this field, more studies and researches are required in future So, potential biocontrol agents can be developed which facilitate sustainable agricultural and organic farming practices.

\section{REFERENCES}

Andrews J.H. and Harris R.F., 2000. The Ecology and Biogeography of Microorganisms on Plant Surfaces, Annual Review of Phytopathology, 38: $145-180$.

Brinkhaus B.M., Lindner D., Schuppan E.G. and Hahn, 2000. Chemical, pharmacological and clinical profile of the East Asian medical plant Centella asiatica, Phytomedicine, 7:427-448.

Delmotte N., Knief C., Chaffron S., Innerebner G., Roschitzki B., Schlapbach R.C.V. and Vorholt J.A., 2009. Community proteogenomics reveals insights into the physiology of phyllosphere bacteria, Proceeding of the National Academy of Science of The United State of America, 106(38): 16428-16433.

Devkota A. and Jha P.K., 2010. Seed Germination responses of the medicinal herb Centella asiatica. brazilian society of plant physiology. 22(1): 143150 .

Fürnkranz M., Wanek W., Richter A., Abell G., Rasche F. and Sessitsch A., 2008. Nitrogen fixation by phyllosphere bacteria associated with higher plants and their colonizing epiphytes of a tropical lowland rainforest of Costa Rica, The ISME Journal Multidisciplinary Journal of Microbial Ecology, 2: 561-570.

Gill S.S. and Tuteja N., 2009. Polyamines and abiotic stress tolerance in plants. Plant Signaling \& Behavior. 5(1): 26-33.

Hashim P., Sidek H., Helan M., Sabery A., Palanisamy U.D. and MohdIlham, 2011. Triterpene Composition and Bioactivities of Centella asiatica, Molecules, 16(2): 1310-1322.
Hayat S., Hayat Q., Alyemeni M.N., Shafi Wani A., Pichtel J. and Ahmad A., 2012. Role of proline under changing environments: A review. Plant signaling and behaviour. 7(11): 1456-1466.

Hirayama T. and Shinozaki K., 2010. Research on plant abiotic stress responses in the post genome era: past, present and future. The Plant Journal. 6(1):1041-1052.

Jalili F., Khavazi K., Pazira E., Nejati A., Rahmani H.A., Sadaghiani H.R. and Miransari M., 2009. Isolation and characterization of ACC deaminase-producing fluorescent pseudomonads, to alleviate salinity stress on canola (Brassica napus L.) growth. Journal of plant physiology. 166(6): 667-674.

James J.T. and Dubery I.A., 2009. Pentacyclic Triterpenoids from the Medicinal Herb, Centella asiatica (L.) Urban, Molecules, 14(10): 39223941.

Kashmira J., Gohil J., Patel A. and Gajjar A.K., 2010. Pharmacological Review on Centella asiatica: A Potential Herbal Cure all, Indian journel of pharmaceutical sciences, 72(5): 546-556.

Katalinic, V., Milos M., Kulisic M. and Jukic, 2006. Screening of 70 medicinal plant extracts for antioxidant capacity and total phenols. Elsevier, 94: 550-557.

Kembel S.W., Connor T., Hubbell S.P., Wright and Green J.L., 2014. Relationships between phyllosphere bacterial communities and plant functional traits in a neotropical forest, Proceeding of the National Academy of Science of The United State of America, 111(38): 13715-13720.

Khan N.A., Khan M.I.R., Asgher M., Fatima M., Masood A. and Saeed S. Salinity Tolerance in Plants: Revisiting the Role of Sulfur Metabolites. Journal of Plant Biochemistry \& Physiology, 2(1).

Knief C., Ramette A., Frances L., Blanco C.A. and Orholt J.A., 2010. Site and plant species are important determinants of the Methylobacterium community composition in the plant phyllosphere, The ISME Journal Multidisciplinary Journal of Microbial Ecology, 4: 719-728. 
Kumar J., Singh S., Singh S., Srivastava P.K., Mishra R.K., Singh V.P. and Prasad S.M., 2017. Transcriptional regulation of salinity stress in plants: A short review. Plant Gene., 11(B):160-169.

Lata R., Chowdhury S. and Gond S.K., 2018. Induction of abiotic stress tolerance in plants by endophytic microbes., 66(4): 268- 276.

Mazinani Z., Zamani M., and Sardari S., 2017. Isolation and Identification of Phyllospheric Bacteria Possessing Antimicrobial Activity from Astragalus obtusifolius, Prosopis juliflora, Xanthium strumarium and Hippocrepis unisiliqousa. Avicenna Journal of Medical Biotechnology. 9(1): 31-37.

Müller T., Müller M., Behrendt U. and Stadler B., 2003. Diversity of culturable phyllosphere bacteria on beech and oak: the effects of lepidopterous larvae. Microbiological research, 158: 291-297.

Negrao S., Schomockel S.M. and Tester M., 2017. Evaluating physiological responses of plants to salinity stress. Annals of Botany, 119,(1): 1-11.

Numan M., Bashir S., Khan Y., Mumtaz R., Khan Shinwari Z., Khan A.L., Khan A. and AL-Harrasi A., 2018. Plant growth promoting bacteria as an alternative strategy for salt tolerance in plants: A review. Microbiological Research, 209: 21-32.

Paul S. and Roychoudhury A., 2017. Effect of seed priming with spermine/spermidine on transcriptional regulation of stress-responsive genes in saltstressed seedlings of an aromatic rice cultivar. Plant Gene., 11(B): 124-132.

Rastogi G., Coaker G.L. and Leveau J.H., 2013. New insights into the structure and function of phyllosphere microbiota through high-throughput molecular approaches, FEMS Microbiology Letters, 348(1):1-10.
Ruppel S., Franken P. and Witzel K., 2012. Properties of the halophyte microbiome and their implications for plant salt tolerance. Functional Plant Biology, 40(9): 940-951.

Ruszymah B.H., Chowdhury S.R., Manan N.A., Fong O.S., Adenan M.I. and Saim A.B., 2012. Aqueous extract of Centella asiatica promotes corneal epithelium wound healing in vitro, Ethnopharmacol, 140(2): 333-338.

Sasidharan S., Chen Y., Saravanan D., Sundram K.M. and Latha L.Y., 2011. Extraction, Isolation and Characterization of Bioactive Compounds from Plants' Extracts. African journal of traditional, complementary and alternative medicines. 8(1):110 .

Singh S., Gautam A., Sharma A. and Batra A., 2010. Centella asiatica (L.): A Plant with Immense Medicinal Potential But Threatened, International Journal of Pharmaceutical Sciences Review and Research, 4(2): 9-19.

Szabados L. and Savoure A., 2009. Proline: a multifunctional amino acid. Trends in Plant Science, 15(2): 1360-1385.

Vorholt J.A., 2012. Microbial life in the phyllosphere, Nature Reviews Microbiology, 10: 828-840.

Wijeweera P., Arnasona J.T. and Koszycki Merali Z., 2006. Evaluation of anxiolytic properties of Gotukola (Centella asiatica) extracts and asiaticoside in rat behavioral models, Phytomedicines, 13(9-10): 668-676.

Xie W.I., Su J.Q. and Zhu Y.G., 2015. Phyllosphere Bacterial Community of Floating Macrophytes in Paddy Soil Environments as Revealed by Illumina High-Throughput Sequencing, Applied and Environmental Microbiology, 81(2): 522-532. 